\title{
Critical Thinking and Value Creating Education for Human Development
}

Tom Destiny Namwambah

Kenyatta University Nairobi, Kenya

DOI: 1 10.36348/jaep.2020.v04i03.007 $\quad$ |Received: 04.03.2020 | Accepted: 13.03 .2020 | Published: 24.03 .2020

*Corresponding author: Tom N. Namwambah

\section{Abstract}

The role of education in human development cannot be overemphasized. To most of us, the basic function of education is to develop, in holistic terms an all-round, well-balanced and self-functioning human person. The emphasis on the intellectual development of the human person is premised on the need to produce an individual capable of translating what is learnt into pragmatic programs as to be able to improve conditions under which we find ourselves and be a better, rational and global citizen. This article explores the need for education in the critical faculty as the best avenue for inculcation of skills, dispositions and traits definitive of value creating education for human development.

Keywords: Human Development Critical Thinking Value Creating.

Copyright @ 2020: This is an open-access article distributed under the terms of the Creative Commons Attribution license which permits unrestricted use, distribution, and reproduction in any medium for non-commercial use (NonCommercial, or CC-BY-NC) provided the original author and sources are credited.

\section{INTRODUCTION}

Bertrand Russell once observed that:

"When you want to teach children to think, you begin by treating them seriously when they are little, giving them responsibilities, talking to them candidly, providing privacy and solitude for them, and making them readers and thinkers of significant thoughts from the beginning. That's if you want to teach them to think."

"Education that transforms is the only education of which it can be truly said that it makes good citizens"

Bertrand Russell - (1872-1970)

Despite our knowledge of the cardinal role education is supposed to serve in human endeavor, we are often hard-put to realize and net the best practices and avenues towards achieving that basic goal. Instead of mid-wifing knowledge, we often force content down the throat of its recipients, suffocating them in the process. Instead of treating the chronic illness of ignorance, we incessantly perpetuate it through spoonfeeding and proselytization. This need to stop.

Socrates, the epitome of perfected pedagogy discovered that by a method of systematic probing questionings, people could not rationally justify their confident claims to knowledge. In our efforts to dispense knowledge in the critical sense, we are often imprisoned by our own egos, incessantly misconstruing appearances as reality. Our attempts to profess knowledge are curtailed by perpetual intellectual limbo occasioned by a mental laxity that banishes our curiosity to unawakening dogmatic slumber. According to Socrates, this is often occasioned by the fact that confused meanings, inadequate evidence and selfcontradictory beliefs often prowl beneath our smooth and yet largely empty rhetoric. In his teaching, Socrates established the fact that we cannot always depend upon those in "authority" to have sound knowledge and insight, and that knowledge is best cultivated in a motivating and mutually cost-sharing and interactive environment. He demonstrated that persons may have power and high position, or even be highly qualified and yet be deeply confused and irrational. In his teaching, Socrates established the importance of asking deep questions that probe profoundly into thinking before any idea is accepted as worthy of knowledge and belief. He was cognizant of the three fundamental conditions necessary for knowledge, namely: i) the belief condition, ii) the truth condition; and iii) the justification condition.

As a criteria for assisting his learners to cultivate knowledge, therefore, Socrates established the importance of seeking evidence, closely examining reasoning and assumptions, analyzing basic concepts, and tracing out implications of not only what is said but of what is done as well. Many centuries after him, Socratic questioning and/or teaching method still stands-out as the best known teaching strategy not only for critical thinking but also for value creating education in human development. His method 
highlighted the need in thinking for criticality, clarity, precision and logical consistency.

In the contemporary world universities are the repositories of knowledge. When we join universities we are supposed to have matured in knowledge, understanding and intellectual etiquette. Universities are meant to be centres of excellence, research, innovation and dissemination of knowledge meant to transform individuals from dependence to independence, individualism to individuality, mediocrity to excellence, naivety to liberal ingeniousness, from meaninglessness to meaningfulness, from ignorance to awareness, and from mere consumers of knowledge to authors and dispensers of knowledge. University education is meant to add value, create a sensible global citizen sensitive to the worth of human existence. With this understanding, I am led to ponder over a number of critical questions:

i) How often do we at the university level take our time to ponder on what education is, its significance, in what it consists and what value we need to achieve when we get to class?

ii) How many of us teach with a view of assisting the learner to discover and cultivate the inner hidden potentials?

iii) How committed are we to pursuing the best practices that education is supposed to serve?

iv) How often do we encourage our learners to listen to their inner voices?

v) How often do we teach for knowledge-fusion away from exam-oriented drilling?

vi) How often do we encourage our learners to ask deep probing questions without taking offence?

vii) What qualities do us, individually or collectively display in order to inspire, motivate and encourage our students to academic enterprise and virtuous citizenshipAre we our students' role models or dreaded despots?

viii) Are we rationally disposed dispensers of value creating knowledge or routine, yellow-paged armchair conveyors of information?

ix) Where, in terms of academic ingenuity, value education and professional etiquette do we stand?

x) Why do we feel debased when our students correct us when we err?

xi) How many of us can claim to be Socrates incarnate?

xii) When we leave our houses to go to work, what motivates us? love for knowledge, love for the subject? Eagerness to keep the job? Fear of losing the job? or a desire to transform society and add value to the worth of human beings and existence?

xiii) How often do we teach our students to think critically through the content of our discipline?

xiv) How interactive are our classes:
These questions are significant to us if we want to produce well developed, highly knowledgeable and competent citizens that the world can depend upon. We are not being compelled to rush into defending ourselves with unwarranted emotional justifications here. The truth is: if most of us were to be put to test we will miserably fail the test to the above questions.

The overall results of a research conducted by Dr. Richard Paul, Dr. Linda Elder and Dr. Ted Bartell in 1995 on 38 public universities and 28 private universities in U.S.A to determine the extent to which faculties put emphasis on critical thinking in their instructions attests to my assumption. The findings of the aforementioned research were as discouraging; indicating that most faculties:

a) do not understand the connection between critical thinking and intellectual standards;

b) are not able to clarify major intellectual criteria and standards;

c) In advertently confuse the active involvement of students in classroom activities with critical thinking in those activities;

d) are unable to give an elaborated articulation of their concept of critical thinking;

e) cannot provide plausible examples of how they foster critical thinking in the classroom;

f) are not able to name specific critical thinking skills they think are important for students to learn in their disciplines;

g) are not able to plausibly explain how to reconcile covering content with fostering critical thinking;

h) do not consider reasoning as a significant focus of critical thinking;

i) do not think of reasoning within disciplines as a major focus of instruction;

j) cannot specify basic structures essential to the analysis of reasoning;

k) cannot give an intelligible explanation of basic abilities either in critical thinking or in reasoning;

1) do not distinguish the psychological dimension of thought from the intellectual dimension;

m) have had no involvement in research into critical thinking and have not attended any conferences on the subject;

n) are unable to name a particular theory or theorist that has shaped their concept of critical thinking.

The overall score of the research showed that although faculties think, only $28 \%$ amongst them think almost correctly, $72 \%$ think wrongly. So as faculties, where are we?

As in our case I won't be surprised if we performed even worse than our counterparts in the United States of America. Most of our lecturers, even though continuously pulled-down by the fatigue of a dismal income, a frustrating working environment, a disharmony occasioned by ethnicised political spillovers at work-stations, never-ending support 
demands from extended families, and socio-economic constrains on the part of the students. These unfavourable factors and many others inherent in our environment have played a negative role on our motivation and aspiration to academic excellence; and the result has been a demotivated lecturers' community with uncaring, casual and a cosmetic approach to an enterprise that ought to be serving and saving humanity.

In Kenya and particularly at the university level the situation is not any better; very little is being done to marry and embrace this ideal within the academic programs. Some efforts have however been made to include critical and creative thinking as a mandatory subject within the curriculum which was pioneered by Kenyatta University from 1987. This timely effort was however premised on a wrong assumption: that taking students through some writings considered bearing a critical outlook is sufficient to transform them into critical and creative spirits [1]. Although the subject is being taught, its recipients still manifest dormancy and unreflective outlook on many of the issues that affects society. This is because the interlocutors of this thought, completely missing the point were convinced that being critical is both logically and empirically associated with being in possession of certain facts about criticism.

To address this glaring misreading, Namwambah in his book Elements and Pedagogy of Critical Thinking [2], posits that fundamental to value creating education and the inculcation of critical and creative thinking skills, the process must proceed from the ability of the lecturers understanding of the concept of critical and creative thinking on the one hand, and of what the subject of critical and creative thinking consists on the other. He further argues that the enterprise of critical and creative thinking is central to the entire spectrum of educational enterprise, and university professors and lecturers will need to undergo refresher courses in order to be able to infuse the concept and its valuable skills within their subjects' domain. He concludes by recommending that critical and creative thinking will make more sense if it's taught within subject domains rather than as a distinct discipline [2].

The recommendation above seems today to being echoed in Kenya's new Competence Based Curriculum (CBC) which emphasizes the essential role of critical thinking in building valuable competences through education. About five years ago, Kenya adopted a new system of education meant to develop competencies and transform its citizens into responsible, innovate and global citizens with skills requisite for the ever changing world. Kenya's new $\mathrm{CBC}$ lays emphasis on the need to enculturate the learners into value based education with a view of cultivating their potentials. As a result, central to this endeavor has been the emphasis on critical thinking as a central component within the curriculum. This emphasis was occasioned by a general observation that rote learning permeated Kenya's previous system of education and therefore there was need to shift the paradigm as to be able to nurture the mind through the infusion of critical thinking within the curriculum in order to produce a holistic global citizen. This undertaking is in its infancy stage and its success will depend on various factors, among them: i) government's readiness to create enabling environment for the flow of and sharing of ideas; ii) Ministry of Education commitment to ensuring that teachers are inducted into best practices and the importance of value creating education through critical and creative approach method; iii) universities and tertiary colleges are well equipped and conversant with the content and methods of teaching and infusing critical and creative thinking in their instructions; and iv) other stakeholders support and appreciate the worth of critical thinking for value creating education.in human development.

To this end, it's clear that both freedom and independence in inquiry are vital in the attainment of knowledge in the critical faculty. It is also clear that critical thinking is one of the main goals of education in the current age, only standing in line with the quest for technological advancement. As a result there is no doubt that critical thinking is a necessary to our understanding of the nature of the educational aims today.

But what exactly is education? Education is basically the means through which a person's state of mind is optimized regardless of the situation as to be able to perceive accurately, think clearly and critically, and act effectively in order to achieve self-selected goals and aspirations instrumental to self-actualization and societal advancement. To this end, education is the process of human growth aimed at nurturing mental abilities and acquisition of skills requisite for rational existence. Thus education plays the role of liberating individuals from ignorance to rationality and selfunderstanding; transforming individuals from individualism to autonomy and individuality; integrating one with the self, nature and society; and spurring development and positive social change. Value creating education is a means to self-actualization, selfdiscovery and self-realization; it is a lever to human emancipation from the shackles of self-miss-definition, self-misconception and self-deception.

Accordingly, the objectives of value creating education should include but not be limited to the full development of human personality in its physical, mental, emotional, and spiritual aspects; inculcation of decorum, responsible and cooperative attitudes; inculcation and development of respect for the dignity of the individual and society; inculcation of patriotism, national pride and integration; development of and widening of individuals' democratic ways of thinking 
and living; development of tolerance, understanding and appreciation towards different ways of life; development and inculcation of a sense of brotherhood and coexistence at social, national and international levels; instrumental to the development of selfconfidence and of the belief that situations may be difficult but not impossible to navigate; development of skills requisite for sound decision making and problem solving, and ability to formulate sound moral principles

Our effort to define education, highlight its basic roles and underscore its objectives is not simplistic, nor is it a naïve attempt to circumvent the importance of value creating education. The words of Barnes [1] on the nature of the human person and the caution to us from Carl Sagan help in our rethinking on the necessity of value creating education for human development. According to Barnes' [1];

"..the human being is the only animal that uses meanings- ideas, concepts, analogies, metaphors, models, theories, and explanations- to make sense of things and to understand, predict, and control things. But again to the contrary she is also the only creature that uses meanings to negate, contradict, and deceive themselves, to misconceive, distort, and stereotype, and to be dogmatic, prejudiced, and narrow-minded. Further, humans are the only animals whose thinking can be characterized as clear, precise, accurate, relevant, consistent, profound, and fair; but at the same time, they are also the only animals whose thinking is often imprecise, vague, inaccurate, irrelevant, superficial, trivial, and biased"'[1].

In relation to critical thinking, human beings are both thinking and unthinking beings. In light to Barnes' paradoxical dichotomies conjecture, we do not simply need to trust our instincts, emotionally informed "knowledge or our sense-derived 'knowledge'. We need not to unquestioningly believe what spontaneously occurs or is thrown at us as "knowledge". We need not accept as true everything that is taught or passed to us by those in authority as true. We need not assume that the experiences of others are unbiased and so worthy of consumption. We also need to be cognizant that our folly and naivety, pride and biases distort and often lead us into self-misconceptions, deceit and thereby garbles our thinking and our ability to access true justifiable knowledge. Education ought to assist us in acquiring positive attitudes in the formulation of intellectually sound standards for belief, truth and validity. This in turn will help us in cultivating habits and traits that will eventually integrate these standards into our lives and help us in the elimination of those obstacles that stand between clear thinking and value education.

The value of education in skills, character and human development has already been underscored. Various seasoned scholars attest to the importance of education and emphasize the many roles education plays in shaping character and transforming individuals and society. My opinion is that value creating education involves the impacting of a complex set of skills, dispositions and attitudes. These skills, dispositions and attitudes, together characterize a virtue which has both intellectual and moral aspects, and which serves to prevent the emergence of numerous vices, including mental laxity, dogmatism, intellectual slumber and prejudice. The cardinal purpose of value creating education to this end is then to empower the recipient with the ability requisite for thinking critically and making rational judgements on controversial issues or questions to which they are likely to have to act.

As stated above, there is a complex set of skills, dispositions and attitudes which characterized value education in the critical faculty. In addition to providing access to impartial supplies of knowledge as the tradition has been, education also needs to offer effective training in judicial habits of thought. To ensure that the knowledge acquired does not produce individuals who passively accept the teacher's wisdom or the creed which is dominant in their own society, the recipients need to develop certain skills far beyond mere access to knowledge; they need to acquire intelligence and not just mere internalized information. This will indicate certain critical abilities education is supposed to impact. Such critical skills grounded in knowledge include: i) the ability to form an opinion for oneself: being able to recognize what is intended to mislead, being capable of listening to rhetoric without being carried away, and becoming adept at asking and determining if there is any reason to think that our beliefs are more true than those of our adversaries; ii) the ability to find an impartial solution: learning to recognize and control our own biases, coming to view our own beliefs with the same rigor and detachment with which we view the beliefs of others, ability to judge issues on their merits, making efforts to ascertain the relevant facts, and having the power of weighing arguments; iii) the ability to identify and question assumptions: learning not to be credulous, applying constructive doubt in order to test unexamined beliefs, and resisting the notion that some authority, a teacher or politician perhaps, has captured the whole truth and therefore should not be questioned.

In nurturing these skills, it's important to remember that our most unquestioned convictions may be as mistaken as those of our opponents. Our account of critical thinking skills should therefore cover grounds highlighted under the dimensions of thought, namely: the purpose for our thinking; the issue, problem or question that need to be addressed; the assumptions on which the issue at hand is founded; the points of view(s) that inform the process of thinking and decision making; the data, information and evidence on which both the assumptions and points of view are derived; the concepts and ideas that are available for reference and application; the inferences or interpretations that can be inferred and or confuted against the issue at 
stake; and the implications and consequences of our thought. This is necessary because our actions are informed by our thinking, which subsequently determines how we are judged.

From the foregoing, we can deduce three critical insights of value creating education: i) the emphasis on judgement, suggesting that critical skills cannot be reduced to a mere formula to be routinely applied but rather, requires that one has to weigh evidence and arguments, and estimate approximate truth. ii) that as an enterprise critical thinking requires being critical about our own attempts at criticism. For example, we need to recognise that refutations are usually preludes to further thinking and refinement and not final products of thought; and that purposive wonder and curiosity is necessary to effective thinking. Critical thinking must include critical reflection on what passes for critical thinking, and iii) critical thinking is not essentially a negative enterprise; our emphasis on constructive doubt, and warning against practices which lead to children becoming destructively critical is positive scepticism. It is important that the kind of criticism aimed at is not just that which seeks to reject, but that which considers apparent knowledge on its merits, retaining whatever survives critical scrutiny.

Secondly, the mere possession of critical skills is not sufficient to make one a critical thinker or full developed individual. There are certain dispositions which guarantee that the relevant skills acquired are actually exercised. These dispositions, habits or practice suggest the actual translation of skills into human behaviour. In this respect education can be understood as the formation, by means of instruction, of certain mental habits and a certain outlook on life and the world. Of great importance among these dispositions are: i) the habit of impartial inquiry: entails the necessity of not admitting or taking at face value one-sided opinions if we are committed to arriving at conclusions which do not depend solely on time and place of our education, often doused with bias and prejudice; ii) the habit of weighing evidence, coupled with the practice of not giving full assent to propositions which there is no reason to believe as true; methodiic or systemic doubt, also called deliberate skepticism; iii) the habit of attempting to see things truly, which contrasts with the practice of merely collecting whatever reinforces existing prejudice; and iv) the habit of living from one's own centre, a kind of self-direction, a certain independence in the will, with caution of not falling victim or prisoner of prejudice. If the latter manifest as the case then there is need for a critical habit of mind to be cultivated

And because these dispositions are not simply automatic responses in which one has been drilled, such intellectual habits in effect reflect a person's willingness or readiness, to act and respond in various ways, which include: i) the readiness to admit new evidence against previous beliefs, which involves an open-minded acceptance of whatever a critical examination has revealed; ii) the readiness to discard hypotheses which have proved inadequate, where the test is whether or not one is prepared in fact to abandon beliefs which once seemed promising; and iii) the readiness to adapt oneself to the facts of the world, as opposed to merely going along with whatever happens.

Beyond the skills and dispositions outlined above, a certain set of attitudes characterize the outlook of a critical person. By critical attitude we mean a temper of mind central to which a certain stance with respect to knowledge, understanding and opinion; it involves: $i$ ) a realization of human fallibility, a sense of the uncertainty of many things commonly regarded as indubitable, bringing with it humility; ii) an openminded outlook with respect to our beliefs, an "inward readiness" to give weight to the other side, where every question is regarded as open and where it is recognized that what passes for knowledge is sure to require correction; iii) a refusal to think that our own desires and wishes provide a key to understanding the world, recognizing that what we should like has no bearing whatsoever on what is; iii) being tentative, without falling into a lazy scepticism (or dogmatic doubt), but holding one's beliefs with the degree of conviction warranted by the evidence. This entails having a strong desire to know combined with great caution in believing that what one knows must meet the test of certainty and proof and an assurance that openmindedness does not degenerate into being mindless.

As a consequence of the above, the critical outlook of value creating education reflects an epistemological and ethical perspective which emphasizes how beliefs are held i.e. not dogmatically; criteria for doubting beliefs, and the belief that knowledge for the freedom of opinion, truthfulness, and tolerance in the critical faculty is possible.

\section{CONCLUSION}

The article has argued for the centrality of critical thinking in value creating education. We have argued for the need to understand that the complexities that characterize human life and the challenges therein can be effectively addressed by designing educational tools, instructions and purposes in such a way that we understand its critical role in human society. The critical thinking component of education is the pacesetter for the worth of education. In our contemporary world, focus is directed on three pertinent things: technological advancement and how to tame its devastating effects; globalization and how it's squeezing the world into a village market and more importantly, how to infuse critical thinking in our educational system with a view of producing men and women who can redirect the world to sanity. This is only possible if critical thinking is given precedence as the safety-valve to value education; an act that will 
spiral the production of men and women who are allround knowledgeable, competent and able to propel the world to the next level. Human beings who believe in the supremacy of reason as the beacon for existence, who have the willingness to spend time reflecting on the ideas presented; with the ability to evaluate and solve problems as they come, who are logical and sequential in thinking without appealing to void emotion, diligent in seeking out and committing to the truth, eager to express their thoughts on a topic without fear or regret; who exercises the highest level of patience, with ability to tolerate ambiguity on understanding that knowledge is tenable. It will help is the inculcation of skills requisite for tolerance, ability to seek alternative views on emerging issues; with the ability to perseveres and endure with a view of attaining truth; individuals who embodies intellectual courage as to pursue issues to their conclusive end, are open to new ideas that may not necessarily agree with their previous thought on a topic or issue and are able to base their judgments on ideas and evidence; a breed of individuals who are able to recognize errors in thought and persuasion, with the ability to recognize good from bad and fallacious arguments; those men and women with the ability to take in criticism without turning personal and myopic; and individuals driven by the passion of leaving the world better than they found it,

\section{REFFERENCE}

1. Wambari, K. (1992). Readings in Introduction to Critical Thinking. NP: NP.

2. Namwambah, T. (2007). Elements and Pedagogy of Critical and Creative Thinking. Shama Books., Addis Ababa Ethiopia. 